\section{Agonistic behavior after stria terminalis lesions in the rat*}

\author{
DAVID A. NOLLEY $\dagger$ \\ Western Michigan University, Kalamazoo, Mich. 49001
}

Rats with anodal lesions centered in the bed nuclei of the stria terminalis were subjected to a pain-elicited fighting paradigm. A transient increase in agonistic behavior was observed in $S$ pairs which were allowed a 6-7-day recovery period and in pairs which were run only $24 \mathrm{~h}$ postsurgery. The increase in reflexive fighting was accompanied by a heightened startle response, which was replaced by shock-elicited stereotyped gnawing behavior when the fighting responses decreased.

In the rat, the stria terminalis (ST) is a major pathway linking the corticomedial amygdaloid nuclei with the ventromedial hypothalamus (Valverde, 1965) and is in close contiguity with the septal area. Stimulation and ablation studies have associated these structures with agonistic behavior (Brady \& Nauta, 1953; Wasman \& Flynn, 1962; Ifilton \& Zbrozyna, 1963; Hernandez.Peón, Chavez-Ibarra, Morgane, \& Timo-laria, 1963). Septal hyperemotionality has focused attention upon the stria terminalis because, as revealed by histology, the ST is of ten damaged in septal lesion procedures producing agonistic behavior (Reynolds, 1965; King, 1958; Wetzel, Comner, \& fevine, 1967). The short duration of septal hyperemotionality has suggested that irritation secondary to the surgical or type of lesioning 'procedure has involved some structure in the vicinity of the septal nuclei, producing the observed irritability (Harrison \& l,yon, 1957). The studies by Turner (.1970) and Thomas \& Yan Atta (1972) eliminated all near-septal structures except the components of the ST in attempts to produce agonistic behavior. Since an increase in pain-elicited fighting accompanies hyperirritability (Ulrich \& Azrin, 1962), pain-licited fighting was used in this study to monitor changes in agonistic behavior brought about by lesions of the bed nuclei of the ST. Additionally, the $\mathrm{Ss}$ were distinguished by the amount of postoperative recovery they received before fighting sessions resumed.

\section{METHOD}

Eighteen male experimentally naive Sprague-Dawley rats, between 110 and

*This research was supported by Grant MH-16995-02 from the Public Health Service and by Grant B008580 from the National Science Foundation to Dr. Frederick P. Gault, Western Michigan University.

†Present address: Brain Research Laboratory, 601 University Ave., Syracuse, N.Y. 13210.
200 days old, were used. The animals were assigned to pairs, concurrent with the requirements of the pain-elicited fighting paradigm. Each pair was matched by weight, which differed between members of each pair by no more than $15 \mathrm{~g}$. Ss were housed individually and were allowed free access to food and water. produced under pentobarbitol inesthesia, using stereotaxically placed insect pins, insulated except for $0.5 \mathrm{~mm}$ at the tip, passing anodal dc through the uninsulated tip. The lesion circuit was completed by a reference electrode clipped to the ear bar. An angular approach at $13 \mathrm{deg}$ from the vertical was utilized, using the coordinates anterior $7.8 \mathrm{~mm}$, lateral $0.6 \mathrm{~mm}$ and $1.6 \mathrm{~mm}$ below zero (Konig \& Klippel, 1963), with a current of $1 \mathrm{~mA}$ for $25 \mathrm{sec}$. A correction, in coordinates, for growth of the brain was made for rats heavier than $200 \mathrm{~g}$. For three sham-lesioned pairs, the electrode was lowered to the same coordinates, but no current was passed. In all cases, both animals of a pair were operated upon on the same day. After sacrifice, the animals were perfused successively with saline and $10 \%$ formol-saline. The brains were sectioned at 50-micron intervals, and the extent of damage was estimated from photographic enlargements, using fresh sections through the extent of the lesions as negatives, modified from the method of Guzman-Flores, Alcaraz, \& Fernandez-Guardiola (1963).

The measure used to record fighting behavior was the cumulative fighting responses observed during each session. Fighting responses were similar to those employed by Bryant (1969). A response was defined as contact made by one or both front paws of one $S$ on the other $S$, inclusive of an area defined by a line between and just behind the ears and running posteriorly to a point where the abused rat's elbow would rest when down and drawn in toward its body. Contacts were not counted if the $S$
Bilateral electrolytic lesions were making the attack had one of its front paws on the grid or if the abused $S$ had not made at least one paw swipe at his attacker during that trial. The $E$ in the observation room recorded fighting responses on a counter and a cumulative recorder, using a hand-operated microswitch. For sessions in which reliability checks were made, a duplicate recording system was used and the two Os sat side by side in front of a one-way glass to approximate an identical view of the animals in the chamber. For three pairs, the first postoperative fighting session was run approximately $24 \mathrm{~h}$ after surgery. For the other three pairs, 6 to 7 postoperative days elapsed before fighting sessions were resumed. With this exception, defined by the postoperative recovery period, all animals were run in daily sessions of pain-elicited fighting. The animals with a recovery period were handled daily for an amount of time equal to that received by the animals with no postoperative recovery.

Pain-elicited fighting sessions were run in a chamber with an effective fighting area of $23 \times 23 \times 29 \mathrm{~cm}$ positioned approximately $7 \mathrm{~cm}$ from the one-way glass. Three walls of the chamber were constructed of plywood; the fourth wall was constructed of $0.9-\mathrm{cm}$ Plexiglas. Chamber illumination was provided by a $15-W$ bulb. Scrambled footshock of 1.0-mA intensity was delivered through a grid floor constructed of $0.9-\mathrm{mm}$ stainless steel. During each session, 120 shocks of $0.5-\mathrm{sec}$ duration were delivered with a 15.0-sec intertrial interval, programmed electromechanically.

The data were arranged into a split-plot analysis of variance (Winer, 1971 , p. 518), with repeated measures on each $S$ in the three groups as levels of one factor. Since postoperative hyperemotionality in the "septal syndrome" is of such a brief duration (Brady \& Nauta, 1955), only the last five preoperative sessions and the first five postoperative sessions were treated as two levels of the other factor in the 2 by 3 analysis.

\section{RESULTS}

In each case, histology indicated that there was bilateral destruction of the infracommissural bed nucleus of the stria terminalis and the dorsal one-third of the medial preoptic nucleus (see Fig. 1 for a representative section). In most cases, the anterior commissure, the precommissural fornix, and precommissural stria terminalis were invaded by the lesion. In several animals, the nucleus and tract of the diagonal band of Broca, the medial forebrain bundle, and the accumbens nucleus were damaged unilaterally.

As illustrated in Fig. 2, there was 


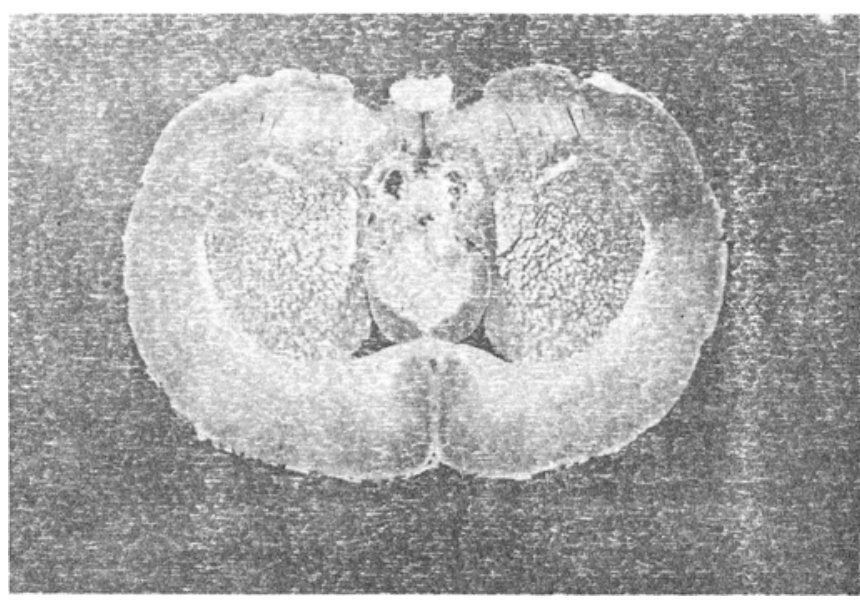

Fig. 1. Typical placement of lesions aimed at the bed nuclei of the stria terminalis. Photo is of maximal damage observed.

significantly more intense fighting in the lesioned animals postoperatively $(\mathrm{F}=22.89, \mathrm{df}=2 / 6, \mathrm{p}<.01)$. The increase was transient, lasting not more than five scssions regardless of the recovery period allowed. Unlike septal-lesioned animals, these Ss rarely provided handling difficulties, either pre- or postsession. However, consistent with symptoms shown in the "septal syndrome," the Ss showed a heightened startle response to auditory, tactual, and gridshock stimuli from the first postoperative day. The heightened startle remained in all pairs until the percent of trials measure subsided. In those animals not sacrificed before a decrement in pain-elicited fighting occurred, stereotyped oral activity, consisting of nosing and biting of the grid floor or any accessible plastic or wood prominence, replaced the startle response in the fight chamber. The stereotyped behavior reliably followed the shock stimulus with a 1 - to $2-\mathrm{sec}$ latency, but ceased before the next shock delivery, and was an aspect of the animals' behavior until sacrifice.

\section{DISCUSSION}

Agonistic behavior in the fight chamber appeared to depend heavily upon an intact startle response to the gridshock. This factor, plus the observation that there was little expression of irritability outside the fight chamber, lends little support for the proposition that the bed nuclei and precommissural components of the ST are primarily concerned with agonistic behavior (Turner, 1970).

The initially heightened startle response could have resulted from transient postoperative irritation of the medial forebrain bundle, a structure which appears to take part in reactivity to electric footshock (Harvey \& Lints, 1965). It is also have shown the transient enhancement in fighting after having received handling identical to the pairs with no recovery period outside of the experimental chamber. For the same reason, degeneration to and subsequent denervation of some other area producing the hypersensitivity, similar to the hypothesized interaction between lesions of the ventromedial hypothalamus (VMH) and denervation of the central gray (Glusman \& Raizen, 1960), is rendered untenable for the results of this study.

The stereotyped oral activity observed in this study is a phenomenon consistently related to an intact VMH (Cox, Kakolewski, \& Valenstein, 1967; Beatty, 1972). Stria terminalis fibers originating in the amygdala form inhibitory synapses upon the VMH (Dreifuss, Murphey, \& Gloor, 1968; Murphey \& Renaud, 1969). Lesions of the ST or VMH p r e e n t a m y g a lo id stimulation-induced suppression of feeding behavior (White \& Fisher, 1969). It is hypothesized that the stercotyped oral behavior reflected a release of inhibition upon VMH mechanisms which facilitate gnawing behavior.

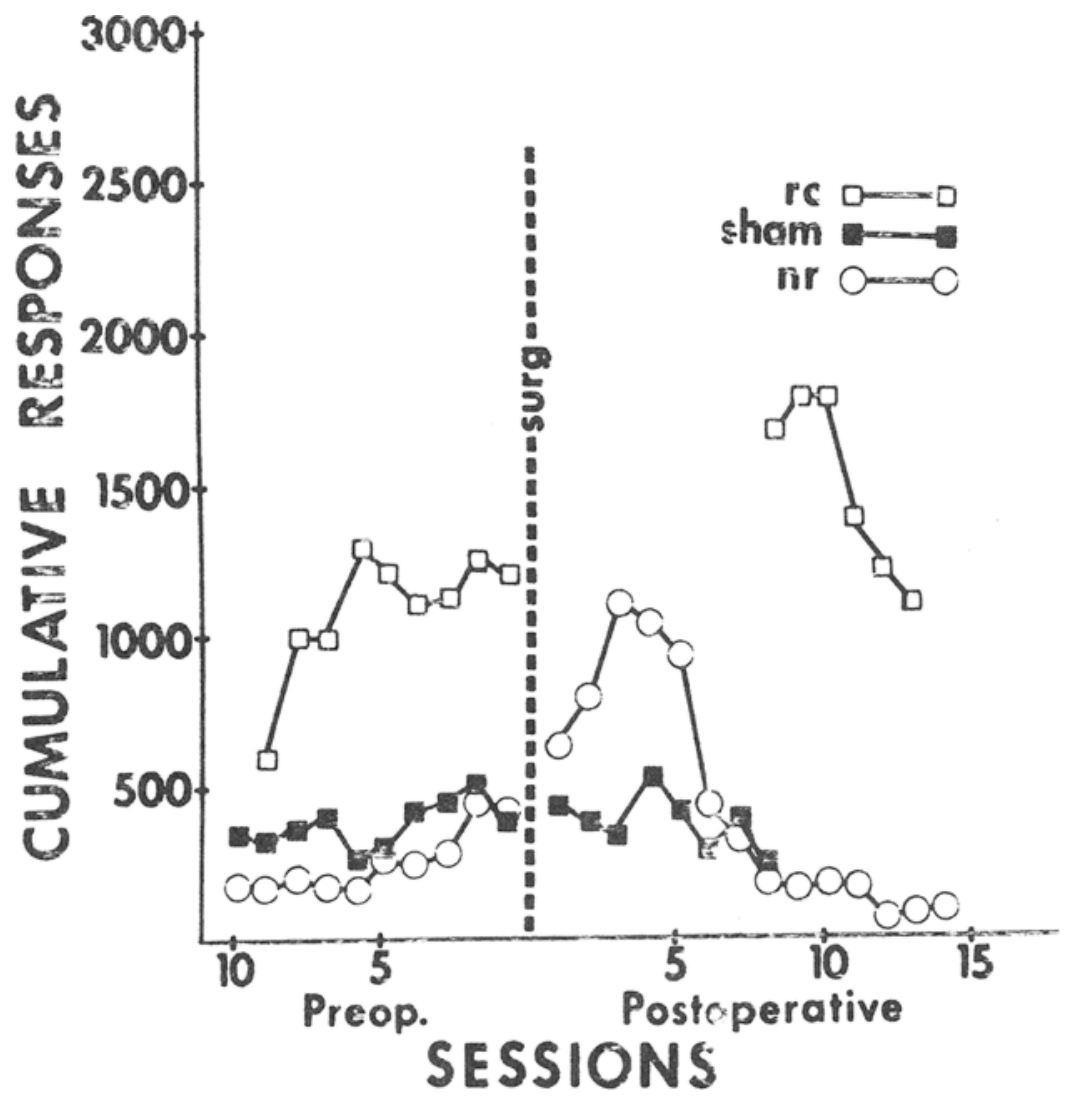

Fig. 2. Cumulative fighting responses observed during each pre- and postoperative session. Groups are: rc-lesioned Ss which received a recovery period; $\mathrm{nr}$-lesioned animals with no recovery period, sham sham-operated Ss. 


\section{REFERENCES}

AHMAD, S. S., \& HARVEY, J. A. Long-term effects of septal lesions and social experience on shock-elicited fighting in rats. Journal of Comparative \& Physiological Psychology, 1968, 66, 596-602.

BEATTY, W. W. Persistent depression of wood-gnawing following ventromedial hypothalamic lesions in the rat. Physiology Behavior, 1972, 8, 383-384. BRADY, J. V., \& NAUTA, W. J. $H$. Subcortical mechanisms in emotional behavior: Affective changes following septal forebrain lesions in the albino rat. Journal of Comparative \& Physiological Psychology, 1953, 40, 339-346.

BRADY, J. V., \& NAUTA, W. J. H. Subcortical mechanisms in emotional behavior: The duration of affective changes following septal and habenular lesions in the albino rat. Journal of Comparative \& Physiological Psychology, $1955,48,412-420$.

BRYANT, J. H. Effects of septal and amygdaloid lesions on pain-elicited fighting. Unpublished MA thesis, Western Michigan University, 1969.

COX, V. C., KAKOLEWSKI, J. W., \& VALENSTEIN, E. S. The relationship between gnawing and food consumption with ventromedial hypothalamic lesions. Physiology \& Behavior, 1967, 2, 323-324.

DREIFUSS, J. J., MURPHEY, J. T., \& GLOOR, $P$. Contrasting effects of two identified amygdaloid efferent pathways on single hypothalamic neurons. Journa of Neurophysiology, 1968, 31, 237-248. GLUSMAN, M., \& RAIZEN, L. Role of the hypothalamus in the organization of agonistic behavior in the cat. Transactions of the American Neurological Association, 1960, 85, 177-181.

GUZMAN-FLORES, C., ALCARAZ, M., \& FERNANDEZ-GUARDIOLA, A. Rapid procedure to localize electrodes in experimental neurophysiology. Boletin del Instituto de Estudios Medicos y Biologicos (Mexico), 1963, 16, 29-31.

HARRISON, J M \& LYON, M. The role of the septal nuclei and components of the formix in the behavior of the rat. Journal of Comparative Neurology, 1957, 108. 121-137.

HARVEY I A \& LINTS, C. E. Lesions in the medial forebrain bundle: Delayed effects on sensitivity to electric shock. Science, 1965, 148, 250-252.

H E R N A.N D E Z - P E O N, R . CHAVEZ-IBARRA, G. MORGANE, P J., \& TIMO-IARIA, C. Limbic cholinergic pathways involved in sleep and emotional behavior. Experimental Neurology, 1963, 8, 93-111.

HILTON, S. M., \& ZBROZYNA, A. W. Amygdaloid region for defense reactions and its efferent pathway to the brain stem. Journal of Physiology, 1963, 165, 160-173.

KING F A Effects of septal and amygdaloid lesions on emotional behavior and conditioned avoidance responses in the rat. Journal of Nervous \& Mental Diseases, $1958,126,55-63$.

KONIG, J. F. R., \& KLIPPEL, R. A. The rat brain: $A$ stereotaxic atlas. Baltimore:
Williams \& Wilkins, 1963.

MURPHEY. J, T., \& RENAUD, I. P. Mechanisms of inhibition in the ventromedial nucleus of the hypothalamus. Journal Neurophysiology, 1969, 32, 85-102.

REYNOLDS, $R$. W. Equivalence of radio frequency and electrolytic lesions in producing septal rage. Psychonomic Science, 1965, 2, 35-36.

THOMAS, J. B.. \& VAN ATTA, L. Hyperirntability, lever-press avoidance, and septal lesions in the albino rat. Physiology \& Behavior, 1972, 8, 225-232.

TURNER, B. H. Neural structures involved in the rage syndrome of the rat. Journal of Comparative \& Physiological Psychology, 1970, 71, 103-113.

ULRICH, R. E., \& AZRIN, N. H. Reflexive fighting in response to aversive stimulation. Journal of the Experimental Analysis of Behavior, 1962, 5, 511-520.

VALVERDE, F Studies on the piriform lobe. Cambridge: Harvard University Press, 1965.

WASMAN, M., \& FLYNN, J. P. Directed attack elicited from hypothalamus. Archives of Neurology, 1962, 6, 220-227.

WETZEL, A., CONNER, R., \& LEVINE, S. Shock-induced fighting in septal lesioned rats. Psychonomic Science, 1967, 9. 133-134.

WHITE, N. M., \& FISHER, A. E. Relationship between amygdala and hypothalamus in the control of eating behavior. Physiology \& Behavior, 1969, 4, 199-205.

WINER, B. J. Statistical principles in experimental design. (2nd ed.) New York: McGraw-Hill, 1971. 